\title{
Analysing Appreciating and Criticizing in Standard Arabic and Saudi Arabic: When Morphology Supports Syntax
}

\author{
Murdhy Alshamari \\ University of Ha'il, Saudi Arabia \\ mr.alshamari@uoh.edu.sa
}

Abdilaziz Homood Albalwi

University of Tabuk, Tabuk, Saudi Arabia

a-albalawi@ut.edu.sa

DOI: http://doi.org/ 10.36892/ijlls.v3i1.492

\begin{tabular}{|c|c|}
\hline $\begin{array}{l}\text { Received: } \\
\text { 04/01/2021 }\end{array}$ & $\begin{array}{l}\text { Abstract } \\
\text { This paper provides a minimalist (Chomsky 2000, 2001) investigation to a }\end{array}$ \\
\hline $\begin{array}{l}\text { Accepted: } \\
06 / 03 / 2021\end{array}$ & $\begin{array}{l}\text { syntactic phenomenon slightly analysed in syntactic research on Standard } \\
\text { Arabic (SA) literature of poetry (TaqiAldin 1987). This syntactic phenomenon } \\
\text { is derived by a construction of a wh-in situ phrase embedded in a construct } \\
\text { state phrase (WICS, henceforth). The novelty about this SA WICS phenomenon }\end{array}$ \\
\hline $\begin{array}{l}\text { Keywords: } \\
\text { construct state } \\
\text { phrase, wh-in situ, } \\
\text { wh-ex situ, } \\
\text { criticising, } \\
\text { appreciating, } \\
\text { morphological } \\
\text { support, pragmatic } \\
\text { device }\end{array}$ & 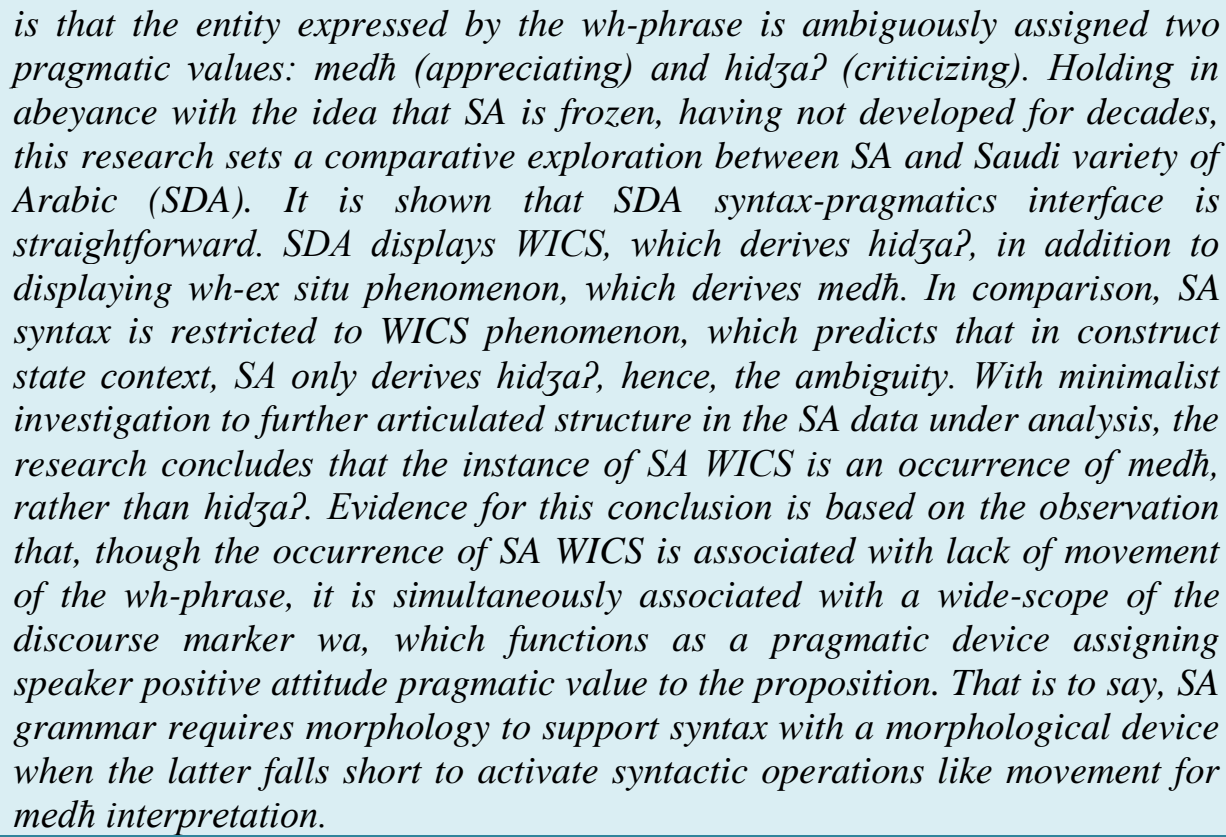 \\
\hline
\end{tabular}

\section{INTRODUCTION}

Impact of discourse marking, marking and encoding extra-propositional information, on the propositional content of the sentence a widely a investigated issue in current minimalist research (Haegeman, 2014; Chomsky 1995, 2000, 2001; Bayer 1996; Ouhalla 1997; Squartini 2013; Bayer \& Struckmeier 2017; Fraser 1999; Blakemore 2002; Cruschina, 2009; Schourup 2011; Alshamari 2017; Jarrah \& Alshamari, 2017; Jarrah, 2019; CheeKeong et al., 2014; Alshamari \& Holmberg 2019). Amongst the widely cross linguistically attested phenomena investigated within the scope of discourse marking in the minimalist research is wh-movement (Ouhalla 1997; Rizzi 1997, 2013; Bošković 2007, 2014; Chomsky 2001; Cruschina 2009; Miyagawa 2010; Citko 2014). Movement, along with agreement, represents a property of human language that indicates its high level of 
expressiveness at the thought perspective (Miyagawa 2010). Movement within theoretical-linguistic considerations is a syntactic operation that is pragmatically motivated and used as an alternative to agreement in instances involving lack of overt agreement. Under this view, movement occurring in syntax (the computational system in generative terms) results in initiating a record to the semanticpragmatic interface (the interpretive system) that there has been an agreement relation held in the computational system between certain items and that a certain interpretation needs to be assigned by the interpretive system. In other words, in formal terms, movement encodes an expressiveness property of a linguistic expression in that it delivers an interpretation of a syntactic item in a way that is more sophisticated in natural language in the sense of Miyagawa (2010). In this way, movement, as a syntax-system to interpretive-system strategy, expresses information-structure, discourse notions like topicalisation, focalisation or speaker's stand, attitude towards the proposition expressed in the utterance (Coniglio 2006, 2008), for instance, and makes available a way of viewing the syntax-todiscourse relation, i.e. how syntax maps to discourse in natural language (Bayer \& Obenauer 2011).

In the spirit of minimalism, i.e., in syntax, movement is viewed as a computational operation, in which a syntactic item appears in a syntactic position different that the syntactic position in which it was first merged and, consequently, is interpreted differently, depending on the peculiar properties of that new, re-merge, syntactic position (Bošković 2007, 2014; Holmberg et al 2017). As languages display various characteristics with respect to movement, this parameter has attracted significant amount of research in the field of modern, generative linguistics (Ouhalla 1991, 1992, 1994, 1997, 1999; Chomsky 1995, 2000, 2001, 2008, 2013, 2019; Shlonsky 2000; Ouhalla \& Shlonsky 2002; Bošković 2007, 2014; Holmberg et al. 2017; Alshamari 2017). In this respect, natural language is divided into two parametric groups within considerations of universal grammar, regulating how whphrase is constructed and processed. These are wh-phrase in-suit and wh-phrase ex-situ.

Grammar of a language displaying wh-phrase ex-suit imposes a condition on syntax that a wh-phrase move to a dedicated position in the discourse domain in the left periphery (but can also be in the clause internal domain, $\mathrm{vP}$ or TP) to get its sematic and pragmatic interpretation, Spec position of FocP or TopP, for instance. In this type of language, a wh phrase moves to get wide scope over the propositional content of the clause and to value a feature on the head position of FocP in a Spec head configuration to agreement (Chomsky 1995; Rizzi 1997). On the other hand, grammar of a language of wh-phrase in-suit doesn't impose such condition on syntax and allows the wh-phrase to be interpreted as such in its first-merge syntactic position (though it is assumed to move at the LF interface system, i.e. covert movement). A typical example of wh-movement is given in the set of examples in (1) below from SDA. ${ }^{1}$

$$
\begin{array}{rll}
\text { (1) a. Anders } & \text { Palaf } & \text { maqalah } \\
\text { DEF-writer } & \text { write.3SG } & \text { article.INDF }
\end{array}
$$

'Anders wrote an article.'

$$
\begin{aligned}
& \text { b. Min Palaf maqalah } \\
& \text { who write.3SG article.INDF } \\
& \text { 'Who wrote an article?' }
\end{aligned}
$$

It is taken that a wh-item moves from its thematic position, where it receives its formal features, including theta roles and re-merges at the position where it is interpreted as Focus. This can be shown along the following lines (we omit irrelevant structure for ease of exposition). ${ }^{2}$

\footnotetext{
${ }^{1}$ Interlinear glossing for all data in this paper is in accordance with Leipzig Glossing Rules available at https://www.eva.mpg.de/lingua/pdf/Glossing-Rules.

${ }^{2}$ The convention $\langle\mathrm{x}\rangle$ means $\mathrm{x}$ is extracted out of the syntactic position $<>$.
} 


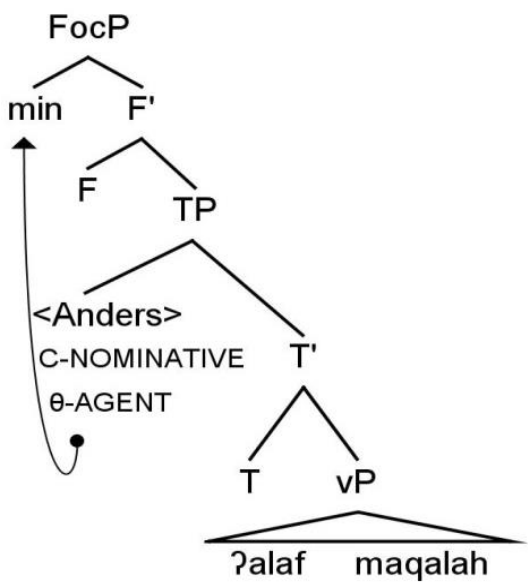

The schema in (2) shows the steps of the derivation at which the clause arguments, subject and object in conjunction with the lexical verb, are first merged in their thematic positions, where the subject, for instance, receives Nominative case and Agent theta-role, depending on the selectivity of the lexical verb. Once this argument-structure phrase has completed, feature-driven operations, including, if any, movement, apply. This can be functional or discoursal. For instance, if the subject DP has in its feature grid a wh-feature [Wh], the consequence is that the subject DP is triggered to move and remerge at a higher syntactic position where it is interpreted as Focus (Rizzi 1997). This scenario results in the subject DP being interpreted at the sematic-pragmatic interface system (LF interface system) as focus and spelled out as wh-item min 'who' at the phonological interface system (PF interface system). ${ }^{3}$ Additionally, in addition to displaying patterns of in-situ phenomenon, SDA exhibits wh-insitu phenomenon, in which the wh-phrase remains in its thematic position and is interpreted as such there. Consider (1a) above, repeated below in (3) with wh-in situ characteristic.

(3) Anders Palaf wif
Anders

'Anders wrote the article.'

The wh-phrase remains in its first-merge position, which could be the case of the wh-phrase remaining in-situ having additional features (though we will not investigate or stipulate the interpretive properties of wh-phrase in-situ here, we will remain in abeyance of the idea that whphrase in-situ phenomenon reflects further discourse characteristics of the relevant wh-phrase. This will be touched on later when comparison between SA and SDA holds).

Having highlighted how a wh-phrase in-situ and a wh-phrase ex-situ are derived and interpreted, and having raised the assumption that the two phenomena seem to show different interpretive properties, the paper will investigate how medh (appreciating) and hidza? (criticizing) are derived in SA poetry. This will be based on an investigation to an instance of WICS in an SA poetry script (TaqiAldin 1987: 302), which has remained determined to ambiguous reading and which has been and unresolved in standard research on SA syntax. The research will implement strategies and mechanisms implemented in the minimalist practice to grammar and will hold comparisons between SA and SDA in some aspects in order to pursue the proposed analyses (Chomsky 2000, 2001).

\section{The inquiry}

\subsection{Background on wh-in situ and minimalist view on construct state}

Before we launch the discussion on the core issue of the research inquiry, it is important to shed light on some characteristics of the derivation of construct state construction in Arabic syntax

\footnotetext{
${ }^{3}$ Throughout the paper, we will use LF 'logical form' which maps the domain of syntax to the domain of the sematic-pragmatic interface system which is responsible for interpreting sematic-pragmatic features of the linguistic product, while we PF 'phonological form' maps the domain of syntax to the domain the phonological, sound interface system which is responsible for interpreting phonological features of the linguistic product.
} 
since it is associated to the syntactic and pragmatic output of WICS phenomenon. To start with, we initially follow Ouhalla (1991) in that a construct state construction is derived by means of merging the constituent expressing possessor at the Spec position of an NP, which contains the lexical items, while the constituent expressing the possessum is merged at the head N of NP. This logic in (4) gives the scenario in (5).

(4)

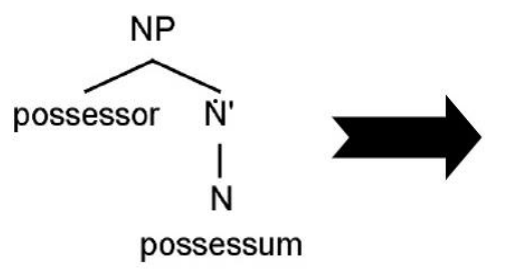

(5)

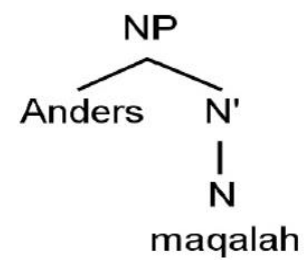

Following Abney (1987) and Ouhalla (1991), the step of the derivation deriving (5) is followed by merging a Possessive Projection, PossP, a functional projection which takes as its sister the lexical projection NP, as in (6). ${ }^{4}$

(6)

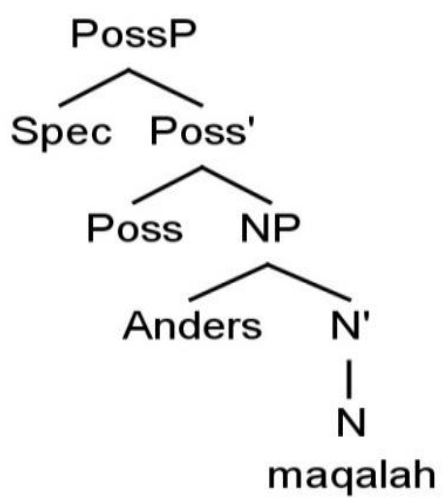

This is followed by movement of the possessum DP maqalah to Spec PossP, as in (7).

(7)

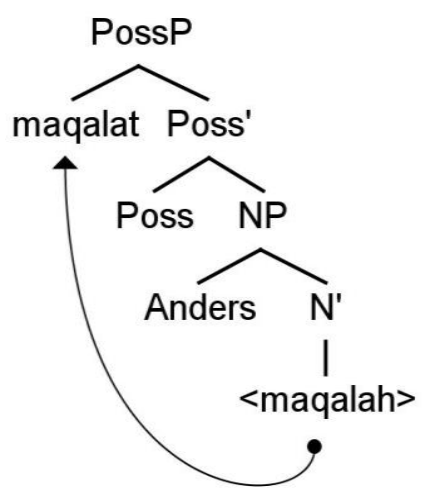

Notice that an agreement strategy applies in (7), which seems to be associated with movement of the possessum DP maqalah, to Spec PossP (Ouhalla 1991). Hence, movement presupposes agreement (Chomsky 2001; 2008; Bošković 2007; Alshamari 2017). This combination of agreement and movement has the consequence that the possessum DP maqalah carries a definiteness marker $t$. Put

${ }^{4}$ See Ouhalla (2011) for more developed work. 
differently, (8) is ungrammatical; the possessum DP maqalah, once moved, cannot be morphologically indefinite.

$$
\begin{array}{rr}
\text { (8) *maqalah } & \text { Anders } \\
\text { Article.INDF } & \text { Anders }
\end{array}
$$

Intended meaning: 'Anders's article.'

Furthermore, the possessum DP maqalah can carry a clitic that agrees in $\varphi$-features with the possessor DP Anders, but under the condition that the possessum DP maqalah also carry the definiteness marker $t$ as in (9) diagramed in (9b). ${ }^{5}$

$$
\begin{array}{cc}
\text { (9) a. maqala-t-uh } & \text { Anders } \\
\text { Article-DEF-3SG.M } & \text { Anders }
\end{array}
$$

'Anders's' article/as for Anders, his article......'

b.

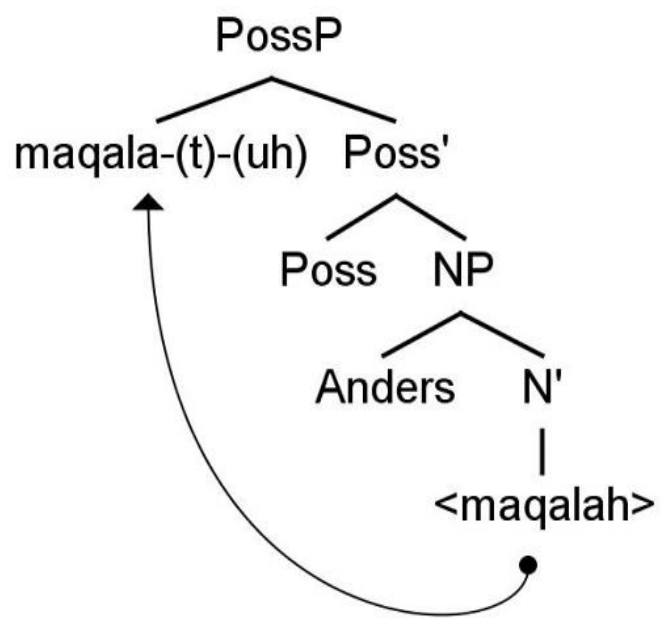

In addition to the definiteness marker $t$, the possessum DP maqalah is suffixed by an agreeing clitic that agrees with the possessor DP Anders (Ouhalla 1991) which we take to be an agreement clitic established in the PossP phrase and expresses topicality or discourse-givenness, following Alshamari (2017). ${ }^{6}$

This characteristic of agreement that possessiveness structure in SDA displays can be further supported by the phenomenon of overtly spelling out the possessiveness feature on the Poss head of PossP at the phonological interface. Consider the set of data in (10). ${ }^{7}$

5 The clitic phenomenon in construct state is extensively investigated in (Ouhalla 1991: 179). He provides the following Standard Arabic example in (i).

(i) kitaabu-ha

Book-her

'Her book.'

Ouhalla (1991) establishes that the agreement-marking clitic $h a$ in (i) realizes the possessor DP, providing morphosyntactic evidence that the possessor DP is internal to the construct state construction, which for Ouhalla (1991) is a pronominal item that incorporates on the $\mathrm{N}$ kitab. This is also found in Alshamari's (2017) topical clitic generalisation', in his work on topic particles which host agreeing clitic but which Alshamari's (2017) 'treats it as a consequence of Agree relation between the relevant topic particle and the DP constituent expressing topic.

${ }^{6}$ The reader can spot the two alternatives in the translation lines. For Alshamari (2017) the clitic $u h$ on the $\mathrm{N}$ maqalat is the spell out of the set of $\varphi$-features of the DP argument that has a [Top] feature of some value, shifting topic, contrastive topic or familiar topic, following Frascarelli and Hinterhölzl (2007). For Ouhalla (1991) it represents referentiality of the relevant DP. Both arguments, on the face of them, argue that the DP expresses discourse-givenness.

7 See Alrasheedi (2019) Arabic and Jarrah et al. (2020) for more insights on Najdi Arabic. 


\author{
(10) a. Pel-kitab mal Anders \\ DEF-book.M Poss.3SG.M Anders \\ 'Anders's book.' \\ b. Pel- muhaz ${ }^{\text {arah }}$ mal-at Anders \\ DEF-lecture.F Poss-3SG.F Anders \\ 'Anders's lecture.'
}

Notice in (10) that the possessive marker mal agrees in $\varphi$-features with the possessum DP Pelmuћaz'arah 'the lecture' in what seems to be a Spec head configuration (Chomsky 1995; Rizzi 1997), providing empirical evidence for the existence a layer of a functional projection PossP above NP (Ouhalla 1991), in par with Ouhalla's (1997) theory of morphological realization of functional heads. Under this view, the possessiveness marker mal is the spell out of [Poss] feature on Poss head of PossP and that Poss head is endowed with a set of $\varphi$-features which results in, for instance, the pattern of agreement malat in (10b), as shown in (11).

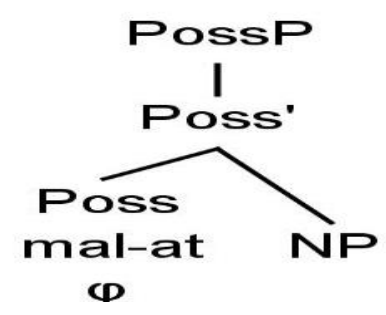

In compliance with (11), (10b) above is represented in (12) below, in which once Poss agrees with the possessum DP, the former triggers movement of the latter to its Spec position, hence, movement presupposes agreement; i.e. agreement is a pre-condition for movement (Chomsky 2001; 2008; Bošković 2007; Alshamari 2017) (dotted line indicates agreement).

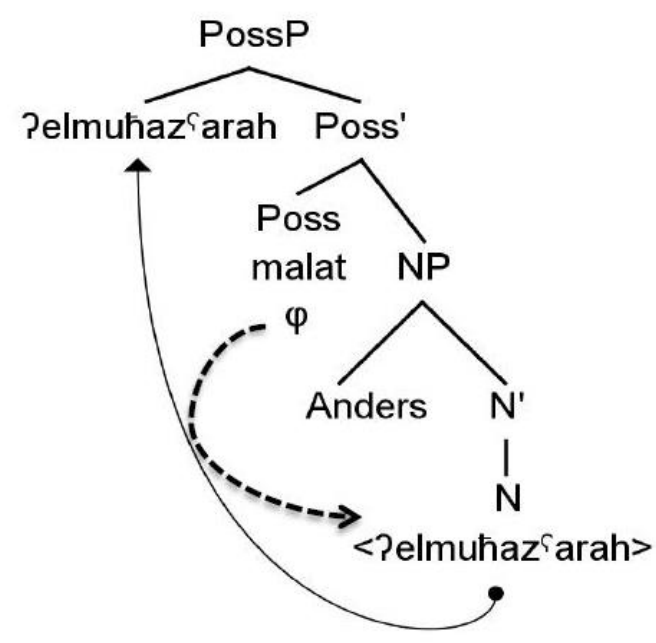

With a fair grasp of the background on the characteristics of construct state phrase, consider the following SDA dialogue involving constructions of wh-movement.

Speaker A1: tamam Anders Palaf maqalah wa 1-muhakim 
Great Anders 3SG-write article and DEF-reviewer happy.3SG.M

'Great! Anders wrote an article and the reviewer is happy.'

Speaker B1: Pa:sif ma simiSt

Sorry Neg hear.PST.1.SG

'I am sorry! I couldn't hear that.

Speaker B2: min maqala-t-uh

Who article-DEF-CL.3SG.M

'Who's article was that?'

Speaker A2: maqala-t Anders

article-Top Anders

'Anders's article.'

(Speaker $C$ just joined the conversation having missed its main topic)

Speaker C: maqala-t $\min$

article-Top who

'Whose article?'

Speaker B2's utterance, syntactically derived by a wh-in situ construction, inquires about whose article the discourse is being held about. The constituent expressing possessum maqala-t-uh now involves the definiteness marker $t$ and the agreeing clitic $u h$ that agrees with the possessor DP Ander. As assumed above in Alshamari's (2017: 100) topical clitic generalisation, spelling out the agreeing clitic $u h$ on the possessum DP expressed as wh-phrase is attributed to the fact that this wh-phrase is D-linked (Rizzi 2013). This means that the question is not rhetoric but based on some shared knowledge in the common ground of the ongoing discourse (Stalnaker 2002). That is, Speaker B asks about a discourse-given entity contrasted against of a set of discourse-given entities that the interlocutors are familiar with. The entWe represent this logic in (14) below, where movement of the wh-phrase is triggered by the Contrastive Topic feature [CT] on it, following Ouhalla (1997).

(14)

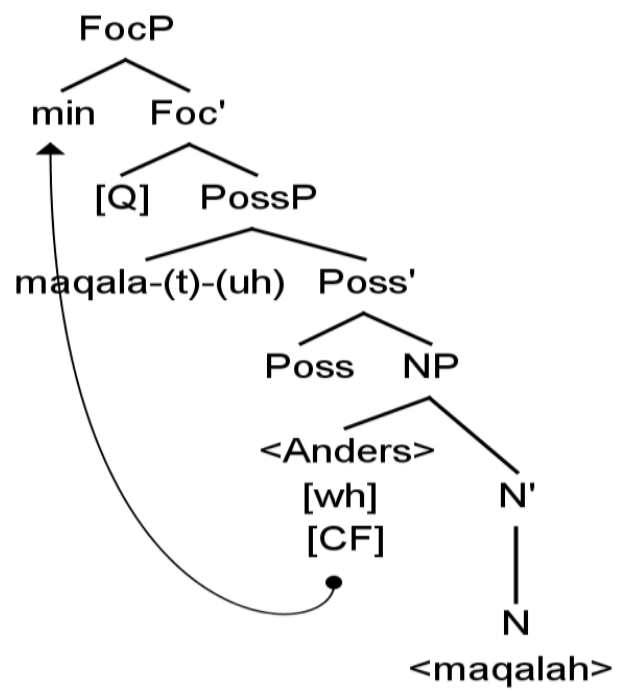


Consider now Speaker C's utterance, in which the possessum DP maqala-t, though still maintaining the definiteness marker $t$, lacks the agreeing clitic $u h$. Entertaining the theory that a clitic is topical (Ouhalla 1997; Alshamari 2017), lack of the agreeing clitic on the possessum DP maqala-t follows from the fact that maqala-t min in Speaker C's utterance doesn't presuppose shared knowledge in the common ground amongst the conversation interlocutors (Holmberg \& Nikanne 2002), which in syntax is processed by non-spelling of the agreeing clitic $h u$.

With this being handy, we now at the stage of introducing the WICS phenomenon used in SA the research will address. The phenomenon will be investigated in conjunction with facts and observations noticed in SDA. The discussion and generalisations we have so far formulated will assist in accounting for the SA phenomenon, with some comparisons being held between SA and SDA as well as some recourse to central theoretical assumptions adopted.

\section{The phenomenon}

We now introduce the piece of SA poet in (15), including the he WICS phenomenon discussed in TaqiAldin (1987: 302). This is represented in glossing in (16).

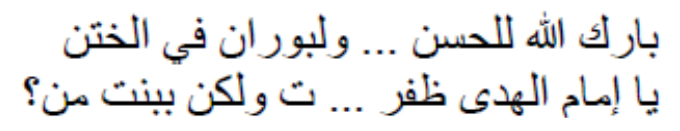

(16) Barak

Allah

1-Lhasan wa li-Borlan

fi-1-xatn

ja

Bless.PST.3SG.M God to-Lhasan and to-Boran on-DEF-Circumcision Voc

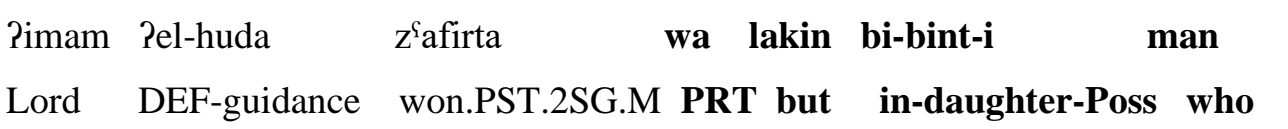

Literal translation: 'May God bless Lhasan and Boran on the event of circumcision (of their son). You lord of guidance. You (Lhasan) have won (engagement with a daughter) but.....whose daughter?'

In (16), on the face of it, the writer offers accreditation to the addressee, 1-Lhasan and his wife Boran, on the event of their son's circumcision, which is a traditional characteristic of Arabic societal protocol at that time. The writer praises Lhasan on his seemingly successful achievement in/luck on his engagement to Boran. However, the boldfaced conjunct involves an instance of WICS, bint-i man . In poetry genre in SA, this wh-construction causes semantic-pragmatic misinterpretation to the text as to whether the writer criticizes or appreciates the entity expressed by the wh-phrase man (TaqiAldin 1987). That is, syntactically, the possessor represented by man, i.e. Boran's father, is a good person, but the interpretation that he is bad also holds. So, in WICS context, man carries an interpretive property widely known as speaker attitude which could be positive or negative towards the proposition or part of the proposition in an utterance (Coniglio 2006, 2008; Zimmermann 2009; Coniglio \& Zegrean, 2010; Alshamari 2017).

The next section involves an investigation to the syntax of this occurrence of WICS within minimalist practice (Chomsky 2000, 2001). Analyses will investigate the pragmatic distribution of the wh-phrase man in bint-i man, along with the particle $w a$, which, as will be seen, has impact on the extra-propositional interpretation of the phrase man. In addition to (16), the next section will take into consideration the two patterns of wh-movement stated in (13B2) and (13C) above. Also, the argument will take into consideration, though will not explicate and elaborate on, the nature of the two varieties used in this paper, SA and SDA. The analyses ahead will stay with the idea that SA, unlike SDA, has been frozen. By the term 'frozen' we mean SA hasn't developed linguistically, for it, for decades, has only been used in literature and holy books (Brustad 2000; Ryding 2005).

\section{Investigating the phenomenon}

It should be stressed here that unlike SDA, SA doesn't exhibit wh-ex situ extracted out of a construct state construction. In other words, the SDA example in (13B2) above, repeated below in (17), is disallowed in SA syntax.

(17) min maqala-t-uh 
Who article-DEF-CL.3SG.M

'Who's article was that?'

The alternative in SA is represented in bold face in (16) being the equivalent of the SDA example in (13C) above, repeated below in (18).

\section{(18) maqala-t $\min$ article-DEF who \\ 'Whose article?'}

We have already established, on intuitive groundings, that (17), unlike (18), is motivated in contexts where the conversation common ground involves shared knowledge and familiarity about the entity expressed by the wh-phrase associated with the DP maqalah. To start with, from a pragmatic perspective, we can generalise that the entity expressed by a wh-phrase ex-situ maintains a degree of speaker positive attitude expressed by the speaker (Struckmeier 2014; Biberauer et al. 2014; Coniglio \& Zegrean, 2010). In comparison, a wh-phrase in a WICS context encodes speaker negative attitude (in bold in (16)). Holding to this intuitive-based generalisation about the interpretive properties of the two patterns of wh-phrase, we now move on to the issue of the merger of discourse marker wa, which we initially attribute to the assumption that $w a$ has a discourse feature overtly encoded in syntax. This discourse feature, we propose, is [SPA] speaker positive attitude in the sense of Struckmeier (2014) and Biberauer et al. (2014).

\subsection{More articulated structure and overt discourse marking: the discourse marker wa}

In research on discourse markers, it is widely held that discourse markers are characterized by the property of being extra-propositional; they don't form part of the canonical structure of the content of the proposition, but they contribute to the propositional content when merged, affecting the discourse domain of the expression, a strategy which maps syntax to the semantics-pragmatics interface (Bayer \& Struckmeier, 2017). Under this view, though they live in syntax, being involved in the numeration of the sentence, discourse markers concern expressive rather than propositional meaning of the sentence (Thumair, 1989; Haegeman, 2014; Bayer, 1996; Ouhalla, 1997; Fraser 1999; Blakemore 2002; Coniglio 2006, 2008; Zimmermann 2009; Paul, 2009; Cruschina, 2009; Coniglio \& Zegrean, 2010; Bayer \& Obenauer, 2011; Zimmermann, 2011; Biberauer \& Sheehan, 2011; Schourup 2011; Biberauer et al. 2014; Struckmeier, 2014; Hack 2014; Bayer \& Trotzke 2015; Bayer \& Struckmeier, 2017; Alshamari, 2017; Jarrah \& Alshamari, 2017). In the minimalist practice of the generative approach to grammar, discourse markers merge at a dedicated, devoted for discourse information, Prt head of PrtP in the sense of Bayer \& Trotzke (2015). This syntactic position where a discourse marker which is located within the CP domain (Rizzi 1997) and whence it wide scopes over the whole propositional content or narrow scopes over part of the propositional content, a phrase or a clause within a sentence.

Research on the script in (16) doesn't consider the pragmatic import of $w a$ in TaqiAldin (1987), in which $w a$ is treated as a kind of prefixed to lakin, though, without any explanation to morphological or morpho-pragmatic motivation to this rather redundant use. This resulted in wa being an observation that has escaped notice in the literature. Bridging this gap in the related literature, we will advocate the proposal that $w a$ functions as a pragmatic device, provided by the morphological component of SA grammar to be used in syntax for encoding speaker positive attitude towards the propositional content of an utterance.

On minimalist syntactic-theoretical groundings, and given the scenarios associated with the data above, let us propose that SA grammar has a constraint on wh-ex situ phrase extraction out of a construct state construction, which we state in (19) below. ${ }^{8}$

(19) SA constraint on wh-movement in construct state construction:

\footnotetext{
${ }^{8}$ This might suggest that a construct state construction is an island, in the sense of Ross (1967). However, we will not take up the issue from this point of view.
} 
A wh-phrase cannot move out of a construct state construction.

With (19) being imposed on SA syntax, we will show that wa is a pragmatic device provided by SA morphology merged in syntax (and probably also morphosyntax) of the SA grammar to back up the syntax which is unable to activate movement of the wh-phrase for certain interpretation, which in our case is speaker positive attitude, medh. Hence, in compensation of lack of movement in SA syntax, SA morphology merges wa which encodes speaker positive attitude in syntax and transfers this interpretation to the interface system for medh interpretation. Consider now the following Quranic verse (?al?aSraf verse: 67).

(20) lajsa b-i safahatu wa lakin-i rasulun min rab-i Pel-\{alami:n

Neg in-SG insaneness PRT but-1SG prophet from God-Gen DEF-creatures

'I am not insane at all but I am the prophet of God sent to all creatures.'

The verse in (20) is an utterance reported from Prophet Hud, in which he denies any insaneness his own people suspect and confirms that, instead, he is a prophet sent from God to them, which is a complement and a privilege that involves honor. The syntax of the discourse marker $w a$ in (20) is represented in (21) below.

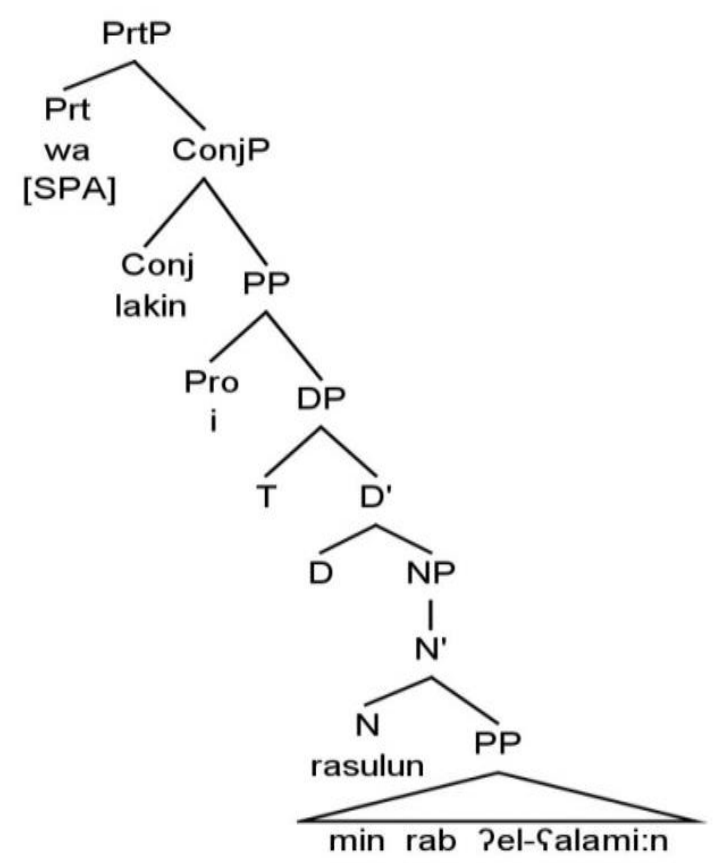

We maintain that the phrase represented by ConjP expresses the state of affairs: 'instead, I am a prophet of God who should not be insane, as you people argue'. Being scoped (c-commanded in syntax) by $w a$, the interpretive property of the phrase expressed by ConjP is now altered, a property of discourse markers (Bayer 1996; Ouhalla 1997; Bayer \& Struckmeier 2017; Fraser 1999; Blakemore 2002; Schourup 2011; Alshamari 2017; Coniglio 2006, 2008; Bayer \& Obenauer 2011). It can now be stated along the lines as 'Honorably, instead, I am a prophet of God who should not be insane, as you people argue'. Given the schemata in (21) and the logic we just highlighted, we propose that the discourse maker $w a$ wide-scopes over the ConjP-phrase and assigns the proposition expressed by the ConjP-phrase a flavor of speaker positive attitude, due to $w a$ being endowed with the [SPA] feature, encoding speaker positive attitude, in generative terms. In light of this proposal and with the generalisations formulated about the phenomena raised in (17) and (18) above, we tackle the issue in (16) implementing feature-based assumptions within the minimalist program seem to be more plausible to account for the phenomenon. 


\subsection{Setting the problem}

Recapitulating, syntax of SA is restricted to displaying the pattern of WICS in (16) and (18), which, as discussed, causes ambiguity of interpretation. As already stressed, SA is frozen, hence, we have lack of intuition enough to judge the interpretive property of the entity represented by the whphrase in (16), that is, the entity expressed by man, Boran's father, being appreciated or criticized. However, as briefly discussed in 3.1, with more articulated structure in the left periphery, i.e., the CP domain, merger of the discourse marker $w a$, and implementing strategies and mechanisms central to minimalism (Chomsky 2000, 2001), recent research has been able to outline common characteristics of structure that has long challenging in pre-generative (Bayer \& Struckmeier 2017). To do this, we advance two proposals in favor of the scenario in the bold chunk in (16), which we represent in (22) below.

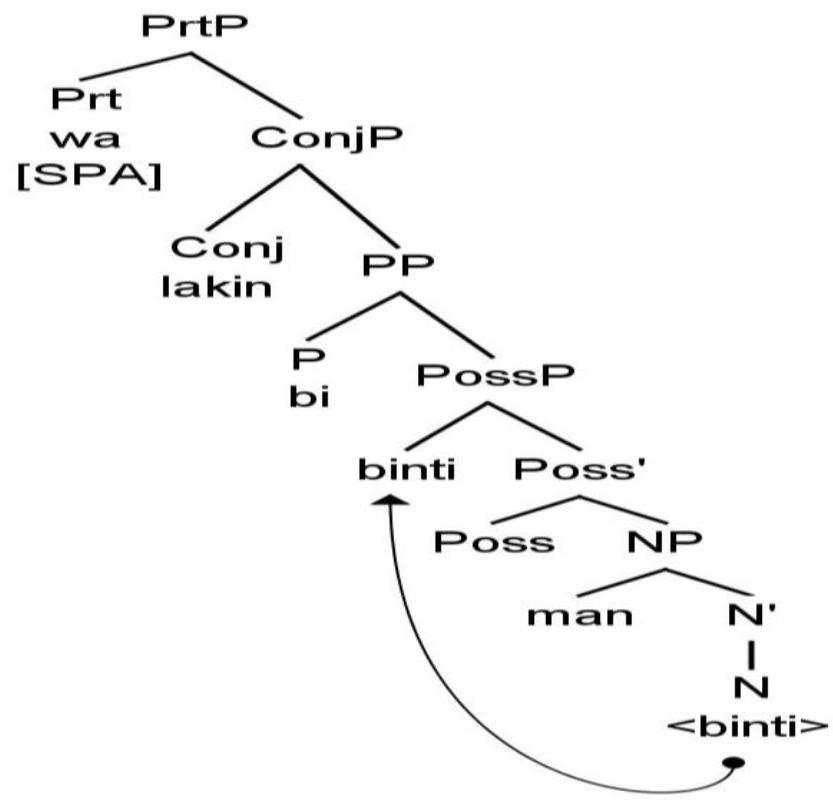

\subsection{Syntactic account}

A syntactic proposal explaining this phenomenon would lie in the assumption that man cannot move across binti since they share the same categorial value, i.e. nominal status, hence, movement of man across binti to the stipulative functional projection XP in (23) below would have caused intervention effects (Rizzi 2013). In other words, unlike SDA which allows for such movement for speaker positive attitude interpretation, SA doesn't allow for this syntactic strategy, as illustrated in (23) below. 


\section{Syntax}

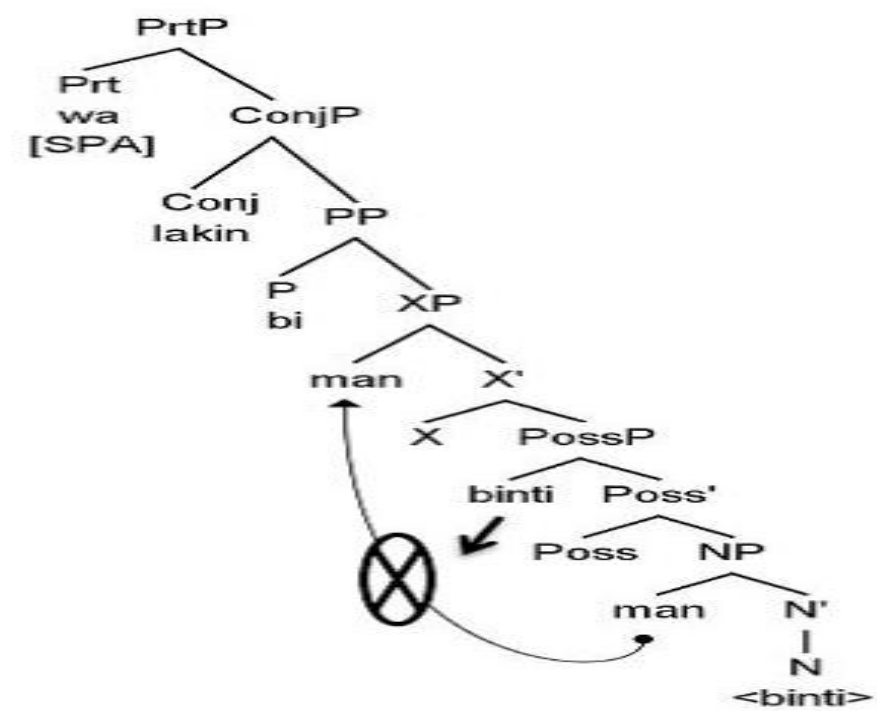

Syntax explains pragmatics and maps the structure to the interface systems for interpretation (Chomsky 2000, 2001). Put differently, it is central to the syntactic theory within the minimalist program that syntactic operations reflect some interpretive properties being established in syntax and contributing to the interpretation at the interface system (Miyagawa 2010). The fact that SA disallows movement of wh-phrase out of construct state while SDA allows such movement so far deduced from the observations above directly moves us to the standard pragmatic phenomena used in SA tradition grammar studies, termed tafreef and tankeer, which we briefly over view in the following subsection.

\subsection{Wh-movement, agreement and cliticisation as a criterion for tafreef and tankeer}

While taSreef is a pragmatic strategy used to value (appreciate) some entity in discourse, tankeer (criticize) is used for the purpose of devaluing. These pragmatic-related processes are activated in the computational component of SA grammar by syntactic and morphosyntactic mechanisms. For instance, in (17), the constituent expressing the tafreefed entity is the possessor DP, min. Marking min with taSreef in (17) is processed by moving it (syntax) and marking the possessum DP magalah with a clitic uh expressing the possessor DP min spelled out on it (morphosyntax). This clitic functions as a record for the interface system to interpret the possessor DP constituent min as being appreciated (speaker positive attitude). In comparison, the construction in (18) doesn't contain this movement; neither does it contain any agreement or cliticisation represented the possessor DP represented as $\min$, which, as a consequence, results in syntax being unable to create a record for the interface system to interpret the possessor DP man as being taSreefed (appreciates. Consequently, the possessor DP man is interpreted as being devalued (criticized).

In this regard, ancient SA Arabs practiced taSreef criterion in poetry and other genera related to literature when they would intend to assign value or give complements to someone. Consider (17) above, repeated below as (24).

(24) min maqala-t-uh

Who article-DEF-CL.3SG.M

'Who's article was that?'

Notice that unlike (18) above, (24) involves cliticisation, a phenomenon which in Arabic, and in language that display cliticisation, is a property of referentiality (Ouhalla 1991), or in other way, topichood (Alshamari 2017). In SDA, in certain contexts, though an entity is shared knowledge, in some cases, the strategy of cliticisation is deactivated; hence, the entity loses the property of being referential or topical in syntax. In this case, where the speaker intends to devalue someone, they 
bleach any agreement marking or cliticisation on the relevant (referential) DP. Consider the following dialogue.

(25) Speaker A1: 1-min hal-Pel-galam

To-Who this-DEF-pen

'Whose pen is this?'

Speaker B: mu $\quad$ 1-i:

Neg to-1SG.M.Poss

'It is not mine.'

Speaker C: 1-i:

to-1SG.M.Poss

'It is mine.'

Speaker A2: min qalam-uh

Who pen-DEF-CL.3SG.M

'Who's pen is this?'

The conversational common ground (Stalnaker 2002) of the context in (25) contains only three speakers, hence, the entities expressed by the DPs, Speaker B and Speaker C, are referential, topical and discourse-given to Speaker A. It follows from this fact that it is unlikely that Speaker A is unaware that the pen belongs to the any of the entities composing the conversational common ground, be it Speaker B or Speaker C. Under this assumption, the felicitous question Speaker A should have asked is in fact Speaker A's second utterance, instead. This would have happened had Speaker A not intended to devalue Speaker C. That is, Speaker A's first utterance, using the dative construction, is for one pragmatic reason: Speaker A shows speaker negative attitude, devaluing, towards Speaker C (criticizing). Reconciling syntactic and interface consequences of (25), what happens in the syntax of (25) is that Speaker A's first utterance lacks any agreement reflex, representing the entity expressing the possessor DP, on the possessum DP. This happens in syntax by deriving the dative phrase l-min. At the PF interface system, any agreement reflex gets null spell out (of clitic or definiteness marker) while at the LF interface system, the full interpretation (Chomsky 2001) of the entity expressed by the possessor, speaker $\mathrm{C}$ receives tankeer interpretation.

With the theory we have so far developed and given the generalisation that non-movement of a constituent associated with lack of agreement and cliticisation is attributed to the pragmatic process that in (16), the speaker, the poet, devalues the entity expressed by the wh-phrase man in binti man, i.e. criticizing it. However, as will be evidenced in the second minimalist proposal in the next subsection, the construction we analyse contains the discourse marker $w a$, which we have just claimed is provided by the morphological component of SA grammar to syntax to encode speaker positive attitude rewards a state of affairs within the propositional content.

\subsection{Minimalist account: morphology supports syntax}

Like the SDA construction in (18), the SA construction in (16), extracted below in (26) doesn't involve movement of the possessor DP, man, neither does it involve agreement on the possessum DP binti, both of which would lead to the conclusion that (16) is an instance of tankeer, hence, hidza?.

(26) wa lakin bi-bint-i man

PRT but in-daughter-Poss who

'But, whose daughter?' 
There is a view that like agreement, movement is a property of human language that is also associated with expressiveness. However, there is growing consensus maintained in minimalist practice to grammar that movement is subject to locality conditions and is not preferred when a certain relation can be processed via agreement. For instance, morphosyntactic operations like cliticisation or morphological operations like merging of discourse markers, if possible, are preferred over movement of a syntactic item since the former is more economical than the latter. In other words, movement is activated when agreement, processed by morphology or morphosyntax, is not possible (Chomsky 2000, 2001; Bošković 2007, 2014; Holmberg et al. 2017). Movement and agreement, then, are linguistic operations activated in syntax, but what is behind the scene is that they are operated for certain discourse reasons related to expressiveness reasons.

We have noticed the variation displayed by SDA in (17) and (18) on the one hand and the pattern displayed by SA in (16) on the other hand. In association to this, we have seen that tafreef and tankeer, in par with medh (appreciating) and hidza? respectively, are pragmatic values achieved in syntax via movement of the tafreefed constituent and non-movement tankeered constituent; i.e., exsitu and in-situ wh-movement, respectively. Movement and non-movement in syntax, then, are the result of such interpretive reasons; syntax does what the interface system imposes on it (Chomsky $1995,200,2001,2008,2019)$. Back to the scenario in (26) and due to lack of intuition on SA and relying on intuition only on syntactic evidence from SDA, as we have said earlier, there is no question that one would tend to interpret the wh-phrase in (26) as being tankeered (criticized), given that the wh-phrase is not moved. With mechanisms provided by the minimalist assumptions and practice, the argument is more of taking a different tack. Looking deeply into the construction, we can see that lakin scopes over its associate DP and contributes its contrasting information to the interpretation of the DP. Under this view, assuming that $w a$ is morphologically part of lakin is redundant; wa doesn't add any further information to the contrasting information already provided by lakin. Additionally, in minimalist considerations, it follows that $w a$ is burden on the computational system, being added for no further value contributing to the derivation. The argument, on empirical groundings, is that $w a$ indeed has its own discourse, pragmatic contribution, but no contrasting import. Evidence supporting this contention comes from the fact that $w a$ can be discontinued from lakin, as witnessed in (27) below:

\section{(27) wa wa-?allah lakin-i xabi:r \\ PRT PRT-Allah but expert.1SG \\ 'But, by God I am an expert.'}

We can see in (27) that the swear phrase wa?allah intervenes between the discourse marker wa and the ConjP headed by lakin, indicating that wa is not part of lakin in morphology. Against this generalisation, we discuss the logic of wa and its pragmatic contribution to ConjP in the following section.

\subsection{Pragmatics property of wa and explanation of its non-movement}

Arabs' use of the morphological strategy of merger of wa in (26) follows from Miyagawa's (2010) philosophy that expressiveness of human language is expressed by overt agreement, which he takes to be the core expressiveness-related part of grammar. It is now common place to hold that in natural language, expressiveness of certain discourse interpretation can be marked via various linguistic means, which Jimenez \& Spyropoulos (2013) propose can be a cooperation amongst the components of grammar. It can be syntactic via movement, phonological via stress and contour, and in some other cases, via morphosyntactic via cliticisation (as in case of topicality) and discourse makers (Bayer 1996; Ouhalla 1997; Bayer \& Struckmeier 2017; Fraser 1999; Blakemore 2002; Schourup 2011; Alshamari 2017; Coniglio 2006, 2008; Bayer \& Obenauer 2011).

The theory we have developed to the WICS phenomenon in (26) is that it is a case of med $\hbar$ (appreciating), not hidza? (criticizing) and that the entity expressed by the wh-phrase man is assigned

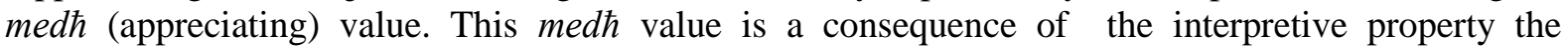
discourse marker $w a$ is endowed with; $w a$ at the PF interface is the morphological realization of the [SPA] feature on the syntactic head of a discourse projection, following (Ouhalla 1997) while it is the 
assigner of speaker positive attitude, i.e., medh, at the LF interface. The representation of (26) is in (28) below.

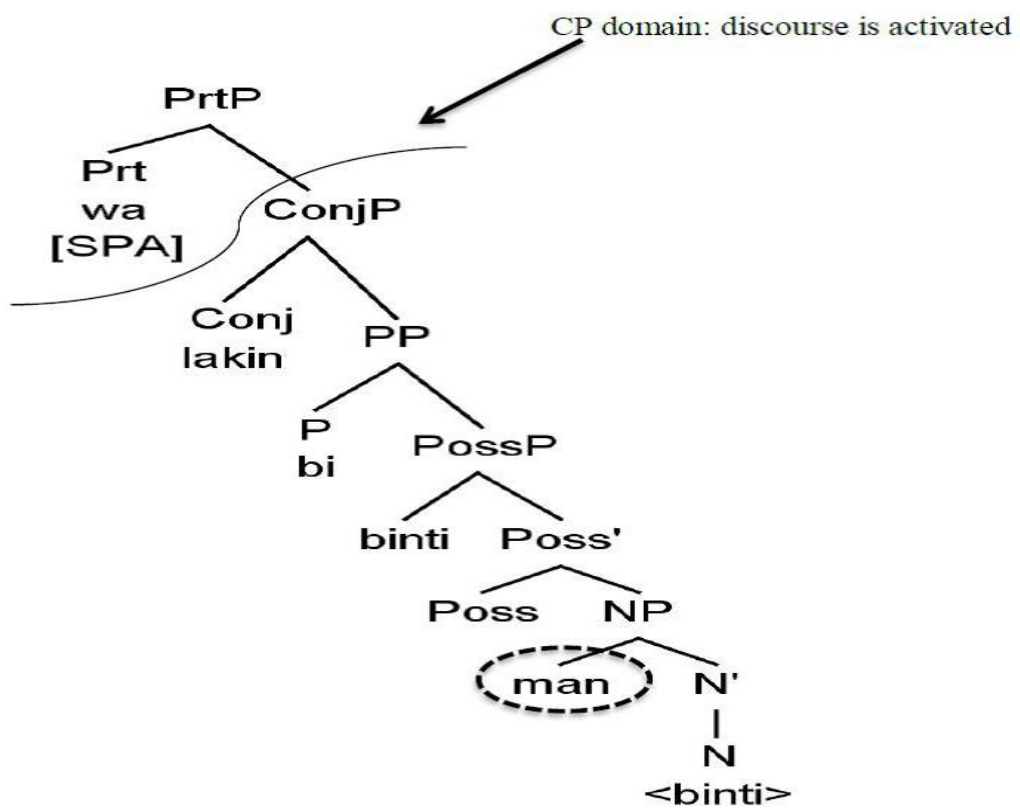

The scenario in (28) shows how syntax maps the derived WICS to the pragmatics interface for med (appreciating) interpretation and how other components of grammar like morphology and morphosyntax assist (assist and back up) in processing the full interpretation of the derivation of the derived WICS we have analyzed.

Recall earlier in the introduction that in case overt agreement, in the strategy of cliticisation, is not possible, syntax activates movement as a record for the LF interface system to render the LF interface system aware that there was an agreement relation held between two items during the course of the derivation, hence, allowing LF interface system to assign an interpretation to the linguistic derivation. This means that the LF interface system imposes conditions on grammar to initiate linguistic operations devoted for certain interpretations, some of which are syntactic, like movement, to compensate for lack of overt agreement (cf. Alshamari 2017). Extending this logic to our story, since med (appreciating) is derived by movement in syntax, but that movement cannot be carried out due to constraint (19) imposed by SA grammar on SA syntax, the LF interface system still needs a record to interpret the output of the derivation med $\hbar$. Remedy to this, we propose, is that SA grammar requires morphology to compensate for lack of movement in the syntactic component, via morphological realization of certain items (Ouhalla 1997), which here is the discourse marker wa. As a result, morphology merges the discourse marker $w a$, which also has a consequence on syntax; that is, syntax activates CP domain, which hosts information related to discourse like information structural notions (Rizzi 1997), which is medh (appreciating). Reconciling all grammar components, then, syntax assists in activating $\mathrm{CP}$ domain, preparing it for hosting the output of the assistance of morphology, the discourse marker $w a$, which, together, are read as medh (appreciating) at the LF interface system rather than hidza?.

\section{Contribution and Implications of the study}

Output of this study raises a few insightful generalisations to minimalism in that components of grammar work as unit in the computational system and also at the interface system, for the optimality of the faculty of language (Chomsky 1995). In case a certain interpretation cannot be delivered by the syntactic component, it can be taken over by the morphological component (Alshamari 2017). This case of morphological support to syntax is a continuation to the attested cases where morphological realization of some features (in the manner of particles or other overt head items) fails to carry out, in which case syntax operates movement. Further, there are cases where 
support of phonological contour and contrastive stress (Ouhalla 1997; Frascarelli and Hinterhölzl 2007; Alshamari 2017) assists in certain interpretation when movement or morphological realization is not possible. Another remark this study gives, with respect to historical change of language, is the assumption that SA shows signs of freezing. A case supporting this contention is the observation that SA doesn't show wh-ex situ phenomenon but, in comparison, its daughter, SDA, doses so, initiating the assumption that SA could have developed movement out of WICS constructions had it not been frozen.

\section{Conclusion}

Implementing minimalist assumptions (Chomsky 1995, 2000, 2001), this paper explored the syntactic strategy of marking med (appreciating) in Standard Arabic (SA), analysing a piece of poetry (TaqiAldin 1987) in SA literature, structured in a WICS syntactic phenomenon, i.e. derived by a construction of a wh-in situ phrase embedded in a construct state phrase. Holding comparative analysis between SA, which has not developed since decades, and its living daughter Saudi Dialect of Arabic (SDA), it is shown that, having developed out of SA, SDA shows movement out of a construct state, hence displaying wh-phrase ex-situ out of a construct state construction. This movement, on intuitive basis, delivers med (appreciating) interpretation, while WICS phenomenon delivers hidza? interpretation. Though SA syntax is restricted to WICS phenomenon, formulating the generalisation that SA only delivers hidza? in WICS, this research argues that the WICS phenomenon under analysis expresses med $\hbar$ rather than hidza?. This logic is arrived at by the observation that the structure of WICS phenomenon consistently contains a discourse maker, wa, whose semantic impart contains speaker positive attitude interpretation, spelling out the feature [SPA] in overt syntax.

\section{References}

Abney, S. (1987). 'The English noun phrase in its sentential aspect'. Unpublished PhD dissertation, Massachusetts Institute of Technology.

Alrasheedi, E. (2019). Possessive constructions in Najdi Arabic (Doctoral dissertation, Newcastle University).

Alshamari, Murdhy. (2017). Topic particles in the North Hail dialect of Najdi Arabic. Newcastle Upon Tyne: Newcastle University (Doctoral dissertation).

Alshamari, Murdhy, \& Holmberg, Anders. (2019). Topic particles, agreement and movement in an Arabic dialect. In 42nd GLOW (Generative Linguistics in the Old World) Conference. Newcastle University.

Bayer, Josef. (1996). Directionality and Logical Form: On the scope of focusing particles and wh-in-situ (Vol. 34). Springer Science \& Business Media.

Bayer, J \& Obenauer, H. (2011). Discourse particles, clause structure, and question types'. The linguistic review 28: 449-491.

Bayer, Josef. \& Trotzke, Andreas. (2015). The derivation and interpretation of left peripheral discourse particles. In Josef. Bayer \& Roland. Hinterhölzl \& Andreas. Trotzke (eds). Discourse-oriented syntax. Amsterdam: John Benjamins Publishing Company. 226: 13-40.

Bayer, Josef \& Struckmeier, Volker (ed.). (2017). Discourse particles: Formal approaches to their syntax and semantics. Walter de Gruyter GmbH \& Co KG, 2016.

Biberauer, T. and Sheehan, M. (2011). 'Introduction: particles through a modern syntactic lens'. The Linguistic Review 28: 387-410.

Biberauer, Theresa, Haegeman, Liliane. and Kemenade, Ans. (2014). Putting our heads together: towards a syntax of particles. Studia Linguistica 68: 1-15.

Blakemore, Diana (2002). Relevance and linguistic meaning: The semantics and pragmatics of discourse markers. Cambridge: Cambridge University Press.

Bošković, Željko. (2007). 'On the locality and motivation of Move and Agree: An even more minimal theory’. Linguistic inquiry 38: 589-644. 
Bošković, Ż. (2014). Now I am a phase, now I am not a phase. Linguistic Inquiry, 45, pp.1-27.

Brustad, K. (2000). The Syntax of Spoken Arabic: A Comparative Study of Moroccan, Egyptian,Syrian, and Kuwaiti Dialects. Georgetown University Press.

CheeKeong, Y., Yassin, A. A., \& Abdulrahma, T. T. A. (2014). Oral communication problems of Yemeni high school EFL students in Malaysia. Journal of Applied Sciences, 14(24), 3620-3626.

Chomsky, Noam. (1995). The minimalist program. Cambridge: MIT Press.

Chomsky, Noam. (2000). 'Minimalist Inquiries: The Framework'. In H. Lasnik, R. Martin, D. Michaels and J. Uriagereka (eds) Step by step.' essays on minimalist syntax in honor of Howard Lasnik. Cambridge: MIT Press.

Chomsky, Noam. (2001). 'Derivation by phase'. In M. Kenstowicz (ed) Ken Hale. A Life in Language. Cambridge: MIT Press. 1-52. Sigurðsson, H.Á. 2009. Remarks on features. Explorations of phase theory: Features and arguments, pp.21-52.

Chomsky, Noam. (2008). On phases. Current Studies in Linguistics Series, 45, p.133.

Chomsky, N. (2013). Problems of projection. Lingua, 130, pp.33-49.

Chomsky, N., Gallego, Á. J., Ott, D. (2019). Generative grammar and the faculty of language: Insights, questions, and challenges. Catalan Journal of Linguistics 229-261.

Citko, B. (2014). Phase Theory: An introduction. Cambridge: Cambridge University Press.

Coniglio, M. (2006). German Modal Particles in the Functional Structure of IP. University of Venice Working Papers in Linguistics 16:57-95.

Coniglio, M. (2008). Modal particles in Italian. Working Papers in Linguistics. 18: 91-129.

Cruschina, S. (2009). The syntactic role of discourse-related features. Cambridge Occasional Papers in Linguistics, 5, 15-30.

Frascarelli, M. \& Hinterhölzl,R. (2007). 'Types of Topics in German and Italian'. In S. Winkler and K. Schwabe (eds.) On Information Structure, Meaning and Form. Amsterdam: John Benjamins. 87-116.

Fraser, Bruce. (1999). What are discourse markers? Journal of pragmatics 31: 931-952.

Hack, F. (2014). The Particle Po in the Varieties of Dolomitic Ladin-Grammaticalisation from a Temporal Adverb into an Interrogative Marker. Studia Linguistica 68: 49-76.

Haegeman, L. (2014). West flemish verb-based discourse markers and the articulation of the speech act layer. Studia Linguistica 68(1): 116-139.

Holly Quran. Ral?aGraf ayah. verse 67.

Holmberg, A \& Nikanne, U. (2002). Expletives, subjects, and topics in Finnish. Subjects, expletives, and the EPP. In Svenonius, P. (ed.) Subjects, Expletives and the EPP. Oxford University Press

Holmberg, A, Sheehan, M \& van der Wal, J. (2017). Movement from the double object construction is not fully symmetrical. Linguistic Inquiry, 50(4), 677-722.

Jarrah, M \& Alshamari, M. (2017). The syntax of the evidential particle fikil in Jordanian Arabic. Italian Journal of Linguistics, 29, 29-56.

Jarrah, M., Altakhaineh, A.R.M. and Al-Rasheedi, E. (2020). Agreement within Construct State in Jordanian Arabic. STUF-Language Typology and Universals, 73(1), pp.1-26.

Jarrah, M. 2019. Record your Agree: A case study of the Arabic complementizer Pinn. Journal of Linguistics, 55(1), pp.83-122.

Miyagawa, S. (2010). Why agree? Why move? Unifying Agreement-Based and Discourse-Configurational Languages. Cambridge: MIT Press.

Ouhalla, J. (1991). Functional Categories and Parametric Variation. London: Routledge. 
Ouhalla, J. (1992). Focus in Standard Arabic: The identification requirement and the Principles of Economy. Ms., Queen Mary and Westfield College.

Ouhalla, J. (1994). Focus in standard Arabic. Linguistics in Potsdam 1: 65-92.

Ouhalla, J. (1997). Remarks on focus in Standard Arabic. In: Mushira. E \& Robert, R, (eds). Perspectives on Arabic linguistics X: papers from the Tenth Annual Symposium on Arabic Linguistics. Amsterdam: John Benjamins. 9-45.

Ouhalla, J. (1999). Focus in Arabic Clefts. In Georges, Rebuschi \& Laurice, Tuller (eds) The Grammar of Focus. Amsterdam: John Benjamins. 335-359.

Ouhalla, J. (2011). 'Preposition-possessum agreement and predication in possessive noun

phrases'. Brill's Journal of Afroasiatic Languages and Linguistics 3: 111-139.

Ouhalla, Jamal. and Shlonsky, U. (2002). Themes in Arabic and Hebrew syntax. Netherlands: Kluwer Academic Publishers.

Paul, W. (2009). Consistent disharmony: sentence-final particles in Chinese. Cambridge Occasional Papers in Linguistics 5: 1-24.

Rizzi, L. (1997). The fine structure of the left periphery. In Haegeman, L. (ed). Elements of Grammar. Dordrecht: Kluwer Academic Publishers. 281-337.

Rizzi, L. (2013). Locality. Lingua. 130: 169-186.

Ryding, K. (2005). A Reference Grammar of Modern Standard Arabic. Cambridge: CambridgeUniversity Press.

Schourup, Lawrence. (2011). The discourse marker now: A relevance-theoretic approach. Journal of Pragmatics 43: 2110-2129.

Struckmeier, V. (2014). Ja doch wohl C? Modal Particles in German as C-related elements. Studia Linguistica 68: $16-48$.

Zimmermann, M. (2009). Discourse particles in the left periphery. ZAS Papers in Linguistics, 35: 543-66.

Zimmermann, M. (2011). Discourse particles. In: Claudia, M. (eds). Semantics: An international handbook of natural language meaning. Berlin: Mouton de Gruyter. 2011-2038.

Coniglio, Marco. \& Zegrean, Iulia. (2010). Splitting up Force, evidence from discourse particles. Linguistics 20: 7-34

Squartini, M. (2013). From TAM to discourse. The role of information-status in north western Italian già 'already'. L. Degand, B. Cornillie and P. Pietrandrea (a cura di), Discourse markers and modal particles. Categorization and Description. Amsterdam, Philadelphia: J. Benjamins, pp.163-190.

Stalnaker, R. (2002). 'Common ground'. Linguistics and philosophy 25: 701-721.

TaqiAldin, A. (1987). Khazantu aladab wa ghajatu alairab. Dar wa maktabat alhilal. Beirut.

Thurmair, M. (1989). Modalpartikeln und ihre Kombinationen. (Vol. 223). Germany: Walter de Gruyter.

\section{$\underline{\text { AUTHORS' BIO }}$}

Murdhy Alshamari is Assistant Professor of Theoretical Linguistics at the University of

Ha'il, Saudi Arabia. He is interested in the minimalist framework of syntactic theory. 
Abdilaziz Homood Albalwi is Assistant Professor of Literature and Criticism at the University of Tabuk, Tabuk, Saudi Arabia. He is interested in Literature and Criticism theories. 